\title{
Design of a diversion structure for the management of residual risks using physical model tests
}

\author{
A. Magnollay \\ BG Consulting Engineers SA, Lausanne, Switzerland \\ G. De Cesare \& R. Sprenger \\ EPFL-LCH, Lausanne, Switzerland \\ D. Siffert \\ Municipality of Delémont, Switzerland \\ P. Natale \\ P. Natale SA, Delémont, Switzerland
}

\begin{abstract}
As revitalization and protection against floods are essential in our time, the town of Delémont in Switzerland has set up a major project named "Delémont Marée Basse". Part of the project, the residual risk plans to be managed by a lateral overflow bypassing the town via the railway platform. A physical model of the area is built at the scale of 1:32 in order to test and optimize the control structure. The main objective of the latter is to protect the town against extreme flood discharges. The main objectives are to derive $15 \mathrm{~m}^{3} / \mathrm{s}$ during a 300 -year flood $\left(150 \mathrm{~m}^{3} / \mathrm{s}\right)$ and avoid overflow for the 100 -year flood $\left(110 \mathrm{~m}^{3} / \mathrm{s}\right)$. After a major calibration phase of water lines, different geometries of the control structure are tested. The retained configuration is optimized for giving results consistent with the requirements of the project. The model was then used to define the minimum overflow area required, the influence of the support piles of the control structure on water lines and diverted discharge, as well as the influence of an upstream apron on Patouillet Bridge. In addition, qualitative tests examined bed load transport impact and driftwood behavior. Similarly, velocity measurements integrate the risk of erosion around the control structure and scour around the bridge piers. Finally, in preparation for the planning of future interventions, overflow discharge values and water lines are recorded under various scenarios.
\end{abstract}

\section{INTRODUCTION}

The Sorne River flows across the town of Delémont in a strongly channeled bed. The project "Delémont Marée Basse" (Delémont low tide) plans to manage the residual risk by a controlled overflow on the right bank downstream of the stadium named "La Blancherie". The overflow reaches the Sorne River again downstream of the town via the railway platform. The overflow structure must protect the city against flooding for high discharges. This structure, which is an important point in the residual risk management, has been tested and optimized to ensure accurate operation.

\subsection{The project site}

The project site is situated on the Sorne River in Delémont, just upstream of the the town center. It is situated on the last sector without any major construction and very close to the railway area. The objective of the diversion project is to use the railway installation as a discharge channel to the Sorne River downstream of Delémont. 
Figure 1 presented the Sorne River in the center of Delémont. At the current stage the river is a concrete channel. The project "Delémont Marée Basse" will transform the river bed. It will allow a higher capacity and a better environmental value. Figure 2 shows the project site with the diversion on the right side.

\subsection{Hydrologic considerations}

The Sorne River is one of the tributaries of the Birse River, which joins the Rhine River in Birsfelden close to Basel. It has a catchment area of $241 \mathrm{~km}^{2}$ at the Delémont gauging station. The discharges to be studied are between 90 and $165 \mathrm{~m}^{3} / \mathrm{s}$ (Fig. 3), which are respectively the values of 30-year return period flood and an extreme flood event (PMF).

\subsection{Past flood events}

Two major observed floods events have been observed in the past century, in 1973 and in 2007 (Fig. 4). In both case the observed discharge was approximately $90 \mathrm{~m}^{3} / \mathrm{s}$.

These two events induced major flooding in the town of Delémont, although the discharge was approximately a 30-year return period flood. A free board of $0.6 \mathrm{~m}$ under the Patouillet Bridge during the 2007 flood has been observed, this value is useful for physical model calibration.

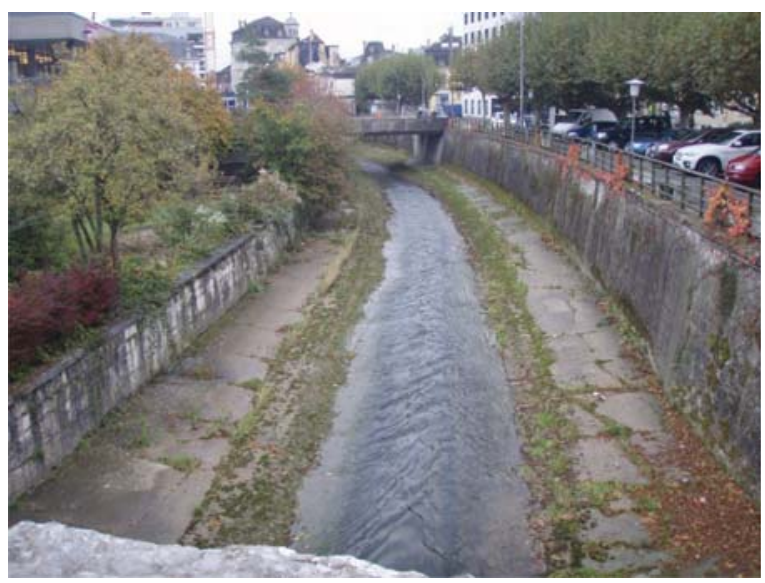

Figure 1. Picture of the channelized Sorne riverbed across the city of Delémont.

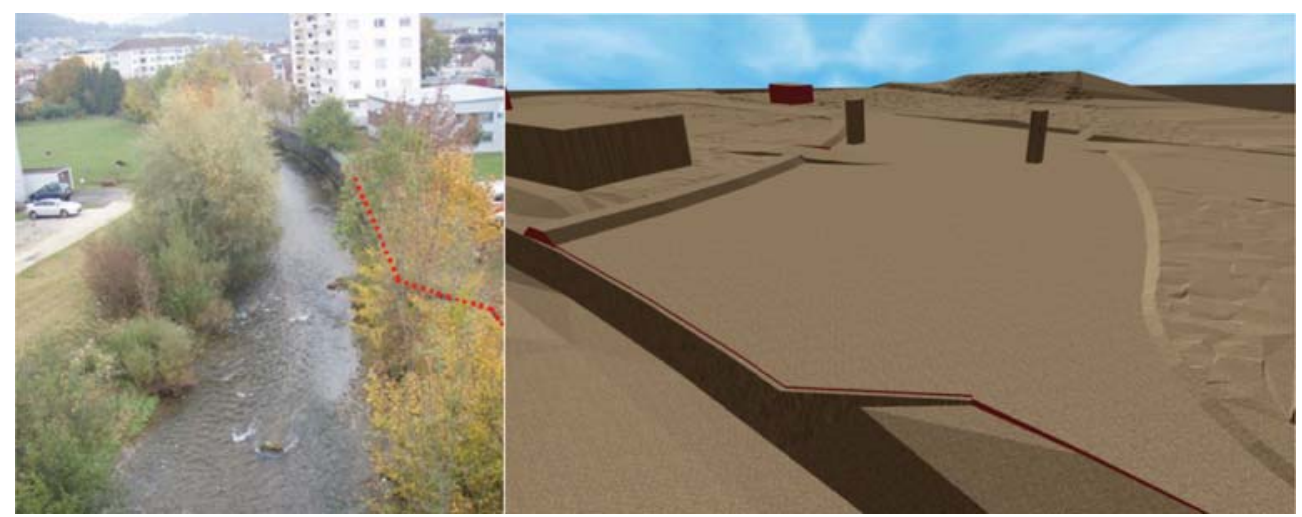

Figure 2. Picture of the project site with the overflow area on its right bank and a 3D view from the river. 


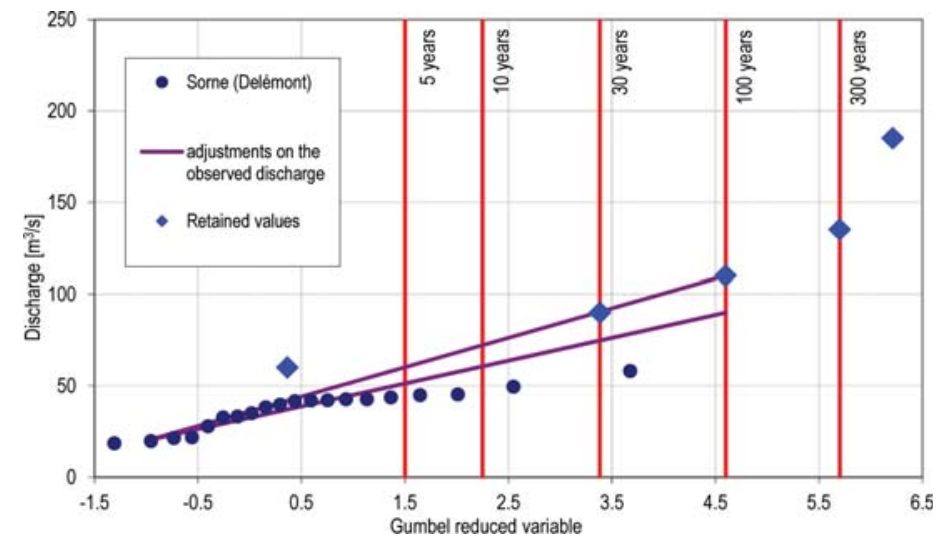

Figure 3. Flood discharge statistics according to a Gumbel distribution and relevant discharge values for corresponding return periods.

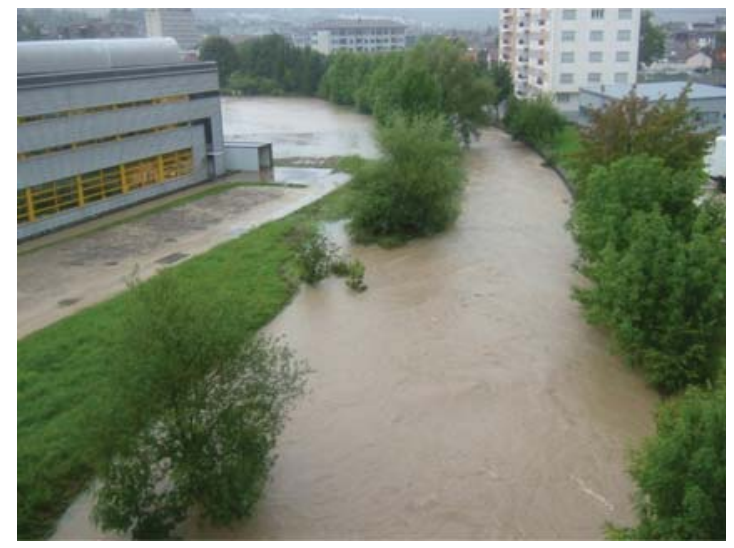

Figure 4. During the 2007 flooding in the Delémont region $\left(\mathrm{Q} \approx 90 \mathrm{~m}^{3} / \mathrm{s}\right)$ - similar view as Figure 2.

\section{PROTECTION OBJECTIVES}

Currently, the capacity of the Sorne River in the center of Delémont is between 70 and $90 \mathrm{~m}^{3} / \mathrm{s}$, but the planned developments will increase the capacity to $135 \mathrm{~m}^{3} / \mathrm{s}$ (200-year flood). The main objectives are to divert $15 \mathrm{~m}^{3} / \mathrm{s}$ during a 300 -year flood $\left(150 \mathrm{~m}^{3} / \mathrm{s}\right)$ and avoid overflowing for the 100-year flood $\left(110 \mathrm{~m}^{3} / \mathrm{s}\right)$.

The diversion should prevent that the discharge in the center of Delémont exceeds the 200 -year flood. This value is the design flood discharge of the future Sorne training development in Delémont.

As the entire project has a revitalization purpose, the derivation scheme should have an impact as low as possible on the river bed and be located on one side of the river only. The operation must be robust and work without any human intervention or mobile parts.

\section{PHYSICAL MODEL TESTS}

A physical model (Fig. 5) is built at the scale of 1:32 respecting Froude similarity. It integrates sufficient upstream and downstream stretches of the Sorne River to satisfy in- and outflow conditions. The model is built with a fixed bed, levees and overflow zone. 


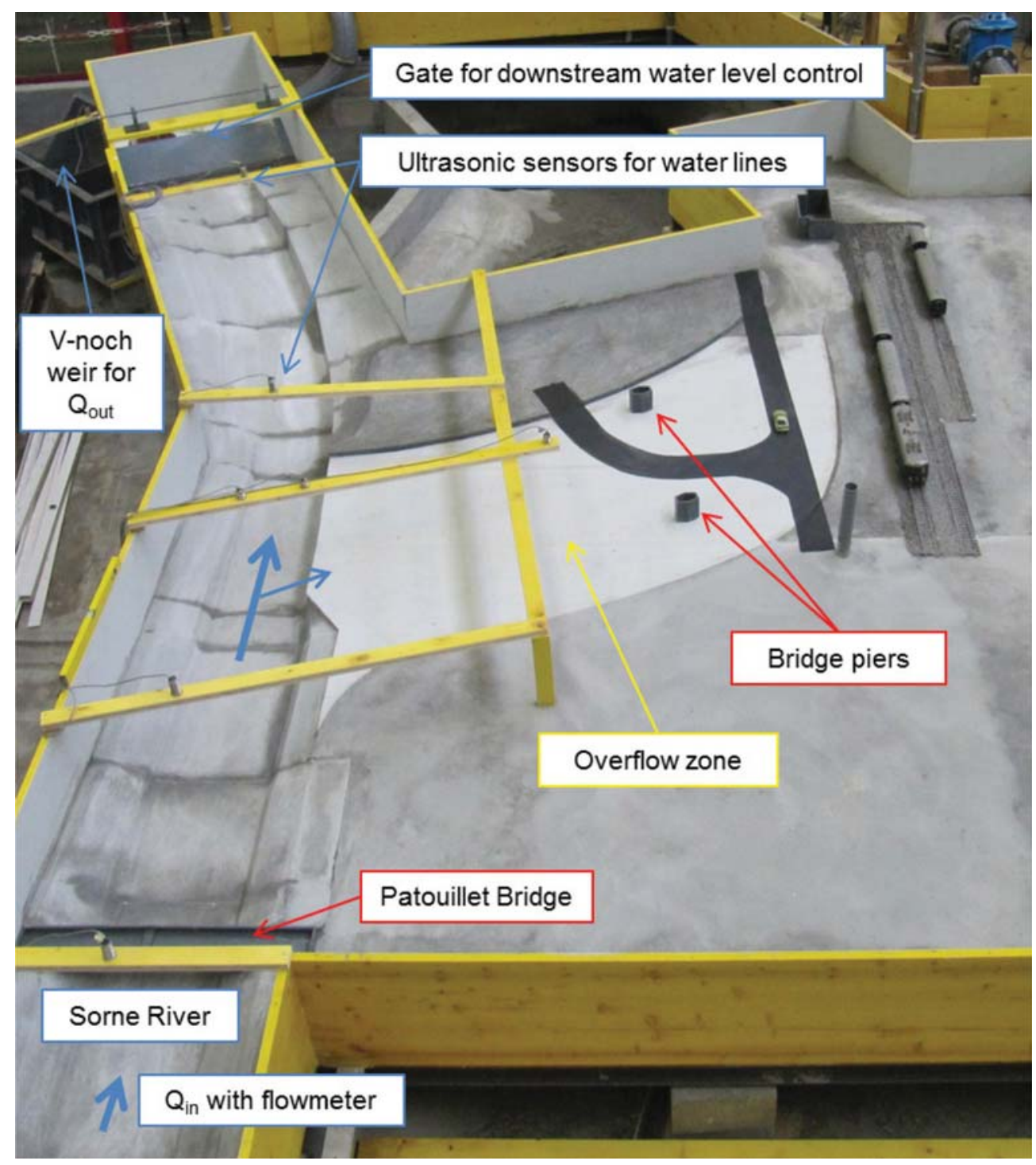

Figure 5. Picture of the physical model in the LCH Laboratory of the EPFL and its main elements.

The lateral overflow zone and constructions influencing the flow such as pressure flow under the Patouillet Bridge, flow separation at bridge piers are also reproduced in the model. The area at the entrance of the Delémont main train station is modelled as well, where the excess flow discharge will enter the railway platform to reach the Sorne River again downstream of the town.

Ultrasonic sensors are used to measure the water lines along the Sorne River and over the overflow zone. Discharge measurements (electromagnetic flow meter and V-notch weir) are used to quantify their distribution.

After a major calibration phase of the model roughness (Baiamonte et Ferro 1997) to obtain compliance with the numerical model HEC-RAS (USACE 2013) and in situ observations during past flood events, flow lines and overflowing discharge values are listed with the Sorne at the current and project state without control structure but with the overflow zone excavated. They help identify overflows to provide the necessary level of raising the banks. This initial configuration does not satisfy the main objectives of flood diversion. 
Then, two different geometries of the control structure are tested. On the second one, a number of parameters are optimized, such as the length and height of the structure. Additional qualitative tests are made on it.

\subsection{Model parameters}

\subsection{Alternatives tested}

Two main geometries of the control structure were tested. The first one (Fig. 6) is a halfmoon structure, conical on the bottom at the right bank just downstream the overflow zone. The left bank creates a flow section reduction as well.

The second control structure tested (Fig. 7) is in the bed of the river, longitudinally located around the middle of the overflow zone. A smooth ramp of the right bank upstream the control structure is also realized.

\subsection{Test Results and retained solutions}

The first geometry of the control structure doesn't give a solution in accordance with the objectives. Its effect on the flow is strictly local and does not increase the diverted discharge rate.

The second geometry of the control structure gives results consistent with the requirements of the project. To achieve these, a number of parameters are optimized, such as the

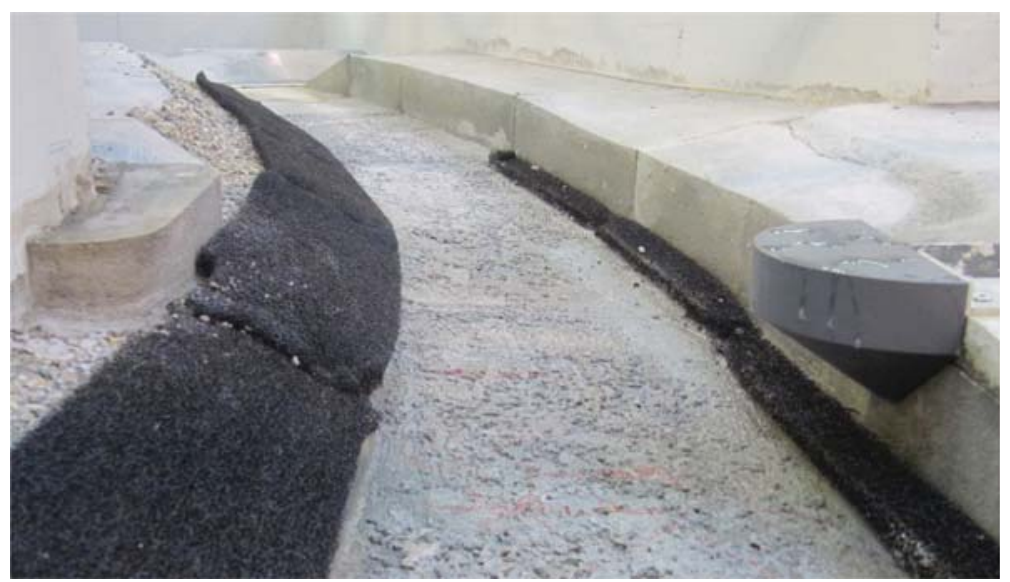

Figure 6. First geometry of the control structure-upstream view.

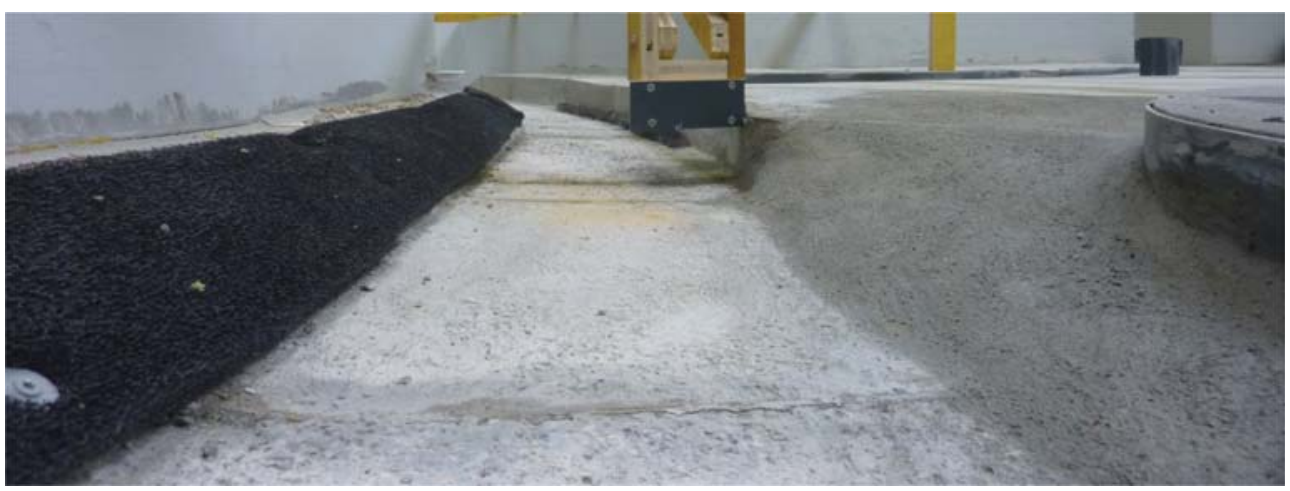

Figure 7. Second and retained geometry of the control structure-upstream view. 
length, the elevation of the lower limit and height of the structure. After optimization, only small waves pass over the overflow zone in the 100 -year flood $\left(110 \mathrm{~m}^{3} / \mathrm{s}\right)$. For a Sorne River discharge of $150 \mathrm{~m}^{3} / \mathrm{s}$, the value of the diverted discharge is $15 \mathrm{~m}^{3} / \mathrm{s}$ (Fig. 8).

The model was then used to define the minimum overflow zone required, regarding the flow velocities concentration on the left side. The required area is 2 to 3 times smaller than the one initially planned, giving flexibility to adapt the excavated area to the land use plan.

A test with two support piles of the control structure in the bed (Fig. 9) shows that the derived discharge is weakly increased for discharges below $150 \mathrm{~m}^{3} / \mathrm{s}$ and that the influence of the piles for discharges above $150 \mathrm{~m}^{3} / \mathrm{s}$ is negligible.

The influence of an upstream apron on the Patouillet Bridge (Fig. 10) is positive (e.g. Jaeggi 2007) for the values of the diverted discharge, decreasing it for a discharge of $110 \mathrm{~m} / \mathrm{s}$ and increasing it for discharges over $135 \mathrm{~m}^{3} / \mathrm{s}$.

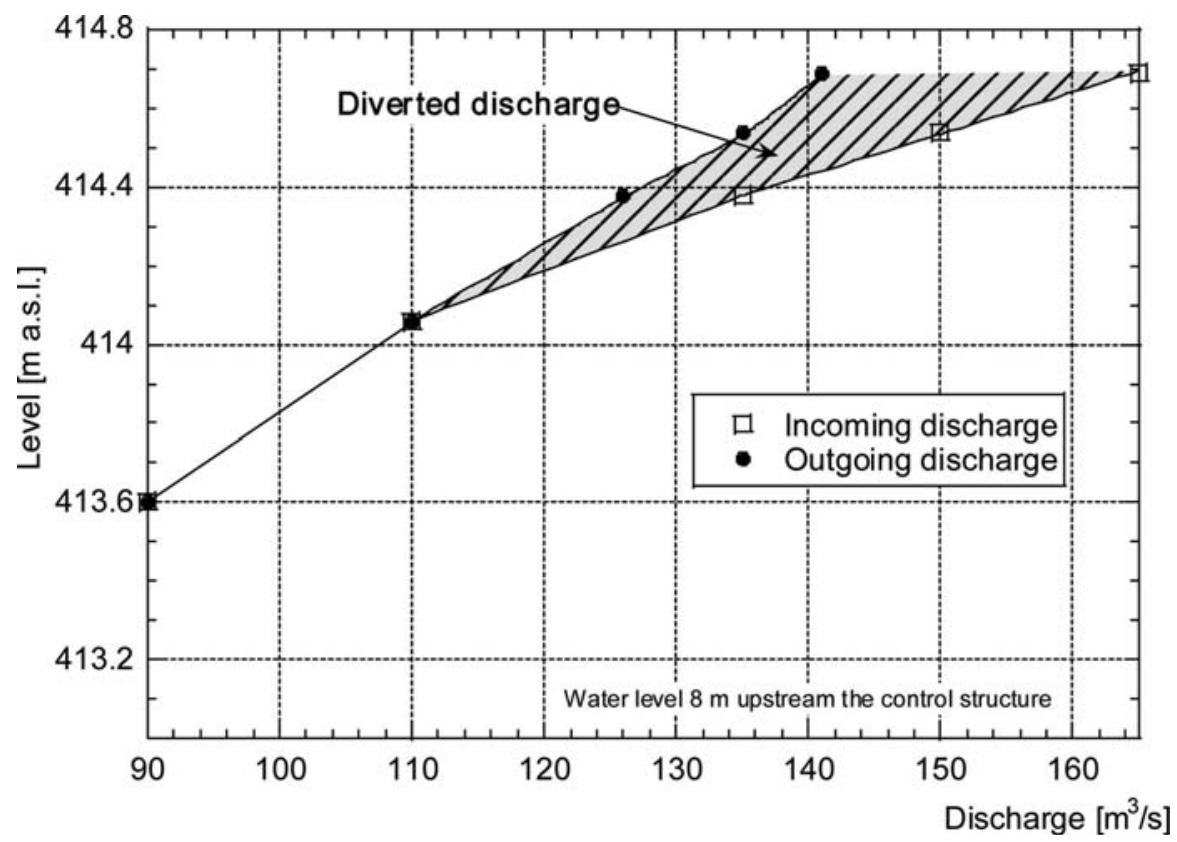

Figure 8. Incoming, outgoing and diverted discharges measurements at the project state with control structure (geometry retained) in relation to water levels $8 \mathrm{~m}$ upstream the control structure.

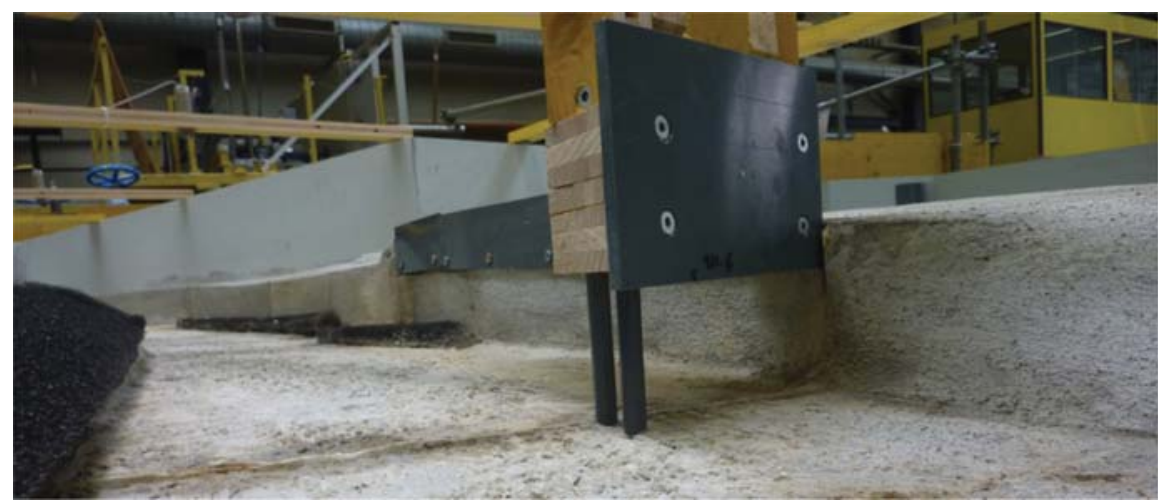

Figure 9. Support piles of the control structure in the river bed. 


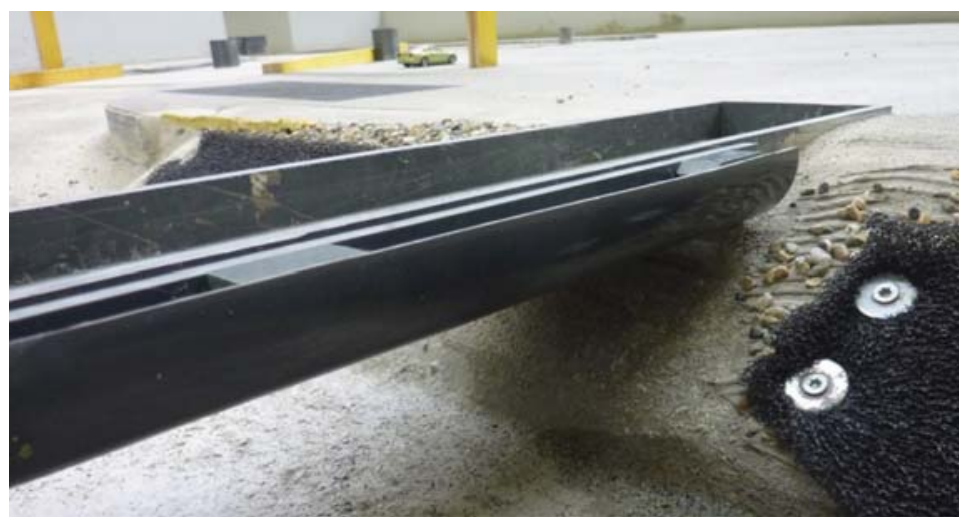

Figure 10. Upstream apron on the Patouillet Bridge.

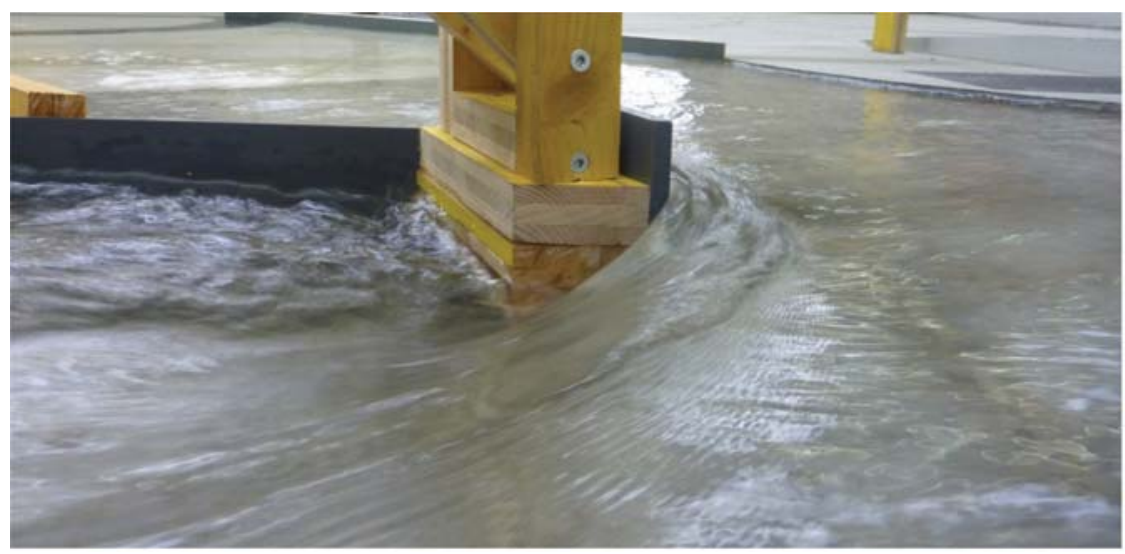

Figure 11. Flow around and below the diversion structure in the physical model $\left(Q_{\text {in }}=135 \mathrm{~m}^{3} / \mathrm{s}\right)$.
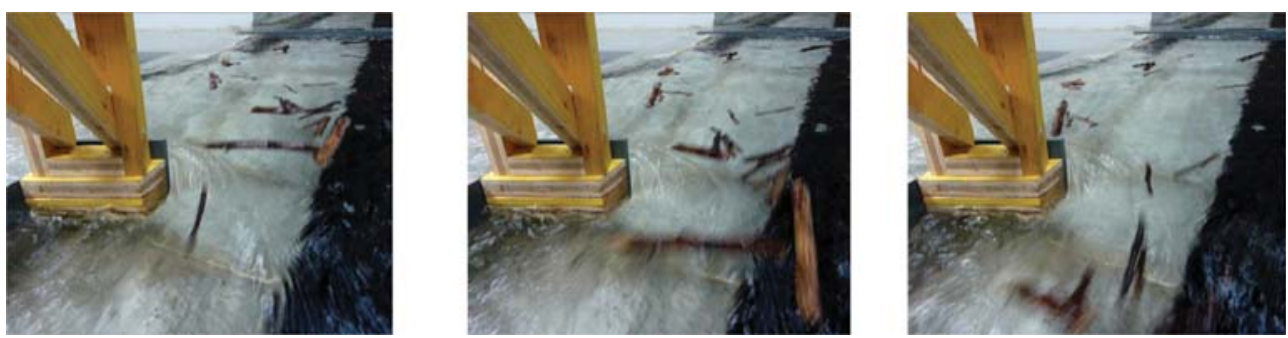

Figure 12. Driftwood around the control structure — downstream view.

At the end, additional qualitative tests showed that bed load transport affects very little the water lines, only locally by amplitude fluctuations of surface waves.

The measurements of flow velocities showed a concentration of flow on the left bank of the overflow zone, with a maximum flow velocity close to $2 \mathrm{~m} / \mathrm{s}$ to a depth of $0.6 \mathrm{~m}$ at a flow rate of $15 \mathrm{~m}^{3} / \mathrm{s}$. Scour around the bridge piers is a critical point and has to be taken into account during design. Similarly, these measures indicate the risk of bottom erosion downstream of the control structure and on the opposite bank. Flow around and below the diversion structure shows these high local accelerations and rather calm lateral overflow (Fig. 11). 
The additional tests showed also, that driftwood and the sediment transport should not disturb the performances of the diversion scheme (Bezzola and Lange 2006). No blockage of the diversion structure could be observed.

Finally, in preparation for the planning of future interventions, overflowing discharge values and water lines are recorded under two different scenarios. In case the control structure is built before the implementation of measures to increase the capacity of the Sorne River through the town, the diverted discharge will increase. In case of removal of the rather heavy vegetation of the upstream riverbanks, the diverted discharge will decrease due to generally lower water levels.

\section{SUMMARY AND OUTLOOK}

The chosen configuration works properly. Indeed, the objective of diverting $15 \mathrm{~m}^{3} / \mathrm{s}$ during a 200 -year flood $\left(150 \mathrm{~m}^{3} / \mathrm{s}\right)$ is achieved. This solution seems to be robust, according to the minor influences of the geometry changes or of the bed load transport.

As a purely numerical approach would not properly represent the diversion work process with sufficient precision the physical model approach has been chosen. The possibility to show the future state of the river, its diversion structure and the simulation of a major flood event to the main stakeholders of the project (administration, politics, engineers, general public, etc.) is another great advantage.

The detailed design of the entire structure is terminated; the costs are estimated at about CHF 700'000. The project should be implemented in 2015. A landscape integration analysis of the control structure and the overflow zone has allowed suggesting some adaptation of the overflow zone that will be used as a parking lot. The slopes marking the topography of the overflow weir will be covered with lose rockfill, symbolizing the passage of water. The upstream petanque field will be renovated and open terraces facing the river will be added. The face of the control structure will be made with an engraved Corten steel plate.

\section{REFERENCES}

Baiamonte, G., Ferro, V. (1997). The influence of roughness geometry and Shields parameter on flow resistance in gravel-bed channels. Earth Surface Processes and Landforms, Vol. 22, 759-772.

Bezzola, G. R., et Lange, D. (2006), Schwemmholz-Probleme und Lösungsansätze, Mitteilungen der Versurchsanstalt für Wasserbau, Hydrologie un Glaziologie, ETHZ, Zürich.

Jaeggi, M. (2007), Sediment transport capacity of pressure flow at bridges, Proceeding of the 32nd congress of the International Association for Hydraulic Research and Engineering, July 1-6, Venice, Italy.

USACE (2013). HEC-RAS Hydrologic Engineering Centers River Analysis System, reference and users manuals. 